\title{
Article
}

\section{Exploiting the Potential in Water Cleanup from Metals and Nutrients of Desmodesmus sp. and Ampelodesmos mauritanicus}

\author{
Roberto Braglia $^{1,+} \mathfrak{D}^{\mathbb{D}}$, Lorenza Rugnini ${ }^{2,+}$, Sara Malizia ${ }^{2}$, Francesco Scuderi ${ }^{1} \mathbb{D}$, Enrico Luigi Redi ${ }^{1}$, \\ Antonella Canini ${ }^{1} \mathbb{D}$ and Laura Bruno ${ }^{2, * \mathbb{D}}$ \\ 1 Botanic Gardens, Department Biology, University of Rome Tor Vergata, 00133 Rome, Italy; \\ roberto.braglia@uniroma2.it (R.B.); francescoscuderiobtv@gmail.com (F.S.); \\ enrico.luigi.redi@uniroma2.it (E.L.R.); canini@uniroma2.it (A.C.) \\ 2 Laboratory of Biology of Algae, Department Biology, University of Rome Tor Vergata, 00133 Rome, Italy; \\ rgnlnz01@uniroma2.it (L.R.); sara.malizia23@gmail.com (S.M.) \\ * Correspondence: laura.bruno@uniroma2.it; Tel.: +39-067259-4332 \\ + These authors contributed equally to this work.
}

Citation: Braglia, R.; Rugnini, L.; Malizia, S.; Scuderi, F.; Redi, E.L.; Canini, A.; Bruno, L. Exploiting the Potential in Water Cleanup from Metals and Nutrients of Desmodesmus sp. and Ampelodesmos mauritanicus. Plants 2021, 10, 1461. https:// doi.org/10.3390/plants10071461

Academic Editor: Dorina Podar

Received: 20 May 2021

Accepted: 13 July 2021

Published: 16 July 2021

Publisher's Note: MDPI stays neutral with regard to jurisdictional claims in published maps and institutional affiliations.

Copyright: (C) 2021 by the authors. Licensee MDPI, Basel, Switzerland. This article is an open access article distributed under the terms and conditions of the Creative Commons Attribution (CC BY) license (https:/ / creativecommons.org/licenses/by/ $4.0 /)$.

\begin{abstract}
Increasing levels of freshwater contaminants, mainly due to anthropogenic activities, have resulted in a great deal of interest in finding new eco-friendly, cost-effective and efficient methods for remediating polluted waters. The aim of this work was to assess the feasibility of using a green microalga Desmodesmus sp., a cyanobacterium Nostoc sp. and a hemicryptophyte Ampelodesmos mauritanicus to bioremediate a water polluted with an excess of nutrients (nitrogen and phosphorus) and heavy metals (copper and nickel). We immediately determined that Nostoc sp. was sensitive to metal toxicity, and thus Desmodesmus sp. was chosen for sequential tests with A. mauritanicus. First, A. mauritanicus plants were grown in the 'polluted' culture medium for seven days and were, then, substituted by Desmodesmus sp. for a further seven days (14 days in total). Heavy metals were shown to negatively affect both the growth rates and nutrient removal capacity. The sequential approach resulted in high metal removal rates in the single metal solutions up to $74 \%$ for $\mathrm{Cu}$ and $85 \%$ for $\mathrm{Ni}$, while, in the bi-metal solutions, the removal rates were lower and showed a bias for $\mathrm{Cu}$ uptake. Single species controls showed better outcomes; however, further studies are necessary to investigate the behavior of new species.
\end{abstract}

Keywords: green microalgae; Desmodesmus sp.; A. mauritanicus; metals; nutrients; bioremediation

\section{Introduction}

The rate of human environmental damage is continuously increasing and represents one of the most urgent challenges we face today. Conventional clean-up techniques, i.e., chemical and engineering-based methods, even if effective, are, in general, very expensive and consist of in-situ and ex-situ interventions, like soil excavation, soil washing or burning, pump and treat systems, solidification with stabilizing agents, vitrification at high temperatures and electrochemical separation. These techniques have some disadvantages considering that they can destroy the soil biotic components and are technically difficult, energy intensive and expensive [1].

An efficient alternative to current environmental clean-up methods is phytoremediation, which can be defined as "the use of green plants and their associated microorganisms, soil amendments and agronomic techniques to remove, contain, or render harmless environmental contaminants" [2]. Among the other remediation methodologies, phytoremediation is one of the most cost-effective, environmentally friendly and low energy consumptions and can be accomplished in situ. Plants have many endogenous genetic, biochemical and physiological properties that make them ideal agents for soil and water remediation [3].

Various hyper accumulative plant species have been extensively investigated that led to substantial progress in this field [4]. Among the many hyperaccumulator species known 
today (about 450 angiosperm species) [5], the Brassicaceae family is the most represented one with the genera Thlaspi, Brassica and Alyssum. There are members of the genus Thlapsi that are known to accumulate $\mathrm{Zn}, \mathrm{Cd}$ and $\mathrm{Pb}$. Another important hyperaccumulator species is Brassica juncea (L.) Czern., which has a great capacity to absorb heavy metals (HM) and to transport them in the aerial organs, although it does not grow spontaneously on metalliferous soils [4-6].

Nevertheless, it is important to mention that most hyperaccumulators are relatively small and have slow growth rates [7]. Ampelodesmos mauritanicus (Poiret) Dur. Et Sch. is an hemicryptophyte caespitosus belonging to the Poaceae family, which can be $1-2 \mathrm{~m}$ high. $A$. mauritanicus form very dense bushes with a 1-m diameter, has erect culms and an angled apex. The flowering period is from April to July. The species has a diffusion through Steno-Mediterranean South-Western Europe and, in Italy, is reported as a spontaneous species in all regions except for Piedmont, Valle d'Aosta, Emilia Romagna, Lombardia, Trentino Alto Adige, Veneto and Friuli Venezia Giulia. It grows along the clay slopes that are generally lapped by humid currents from sea level up to $1200 \mathrm{~m}$ [8].

Consequently, it is a plant highly resistant to insolation, drought, temperature variability [9]. Algae-based remediation (phycoremediation) techniques exploit the natural ability of cyanobacteria, macro- and microalgae to remove organic/inorganic pollutants (such as nutrients and metals) from wastewater $[10,11]$ when present at concentrations between 1 and $100 \mathrm{mg} \mathrm{L}^{-1}$, where conventional methods are insufficient [12,13]. The idea of using microalgae to treat wastewater was introduced in 1957 by Oswald and Gotaas [14], and since then numerous studies have underlined how efficient microalgae remediate highly polluted waters and how they can be incorporated into traditional wastewater treatment processes [15].

Several studies have demonstrated the ability of different green microalgal species to remove both nutrients and HM from polluted media, in particular Chlorella sp., Scenedesmus sp., Desmodesmus sp. and Chlamydomonas sp. [16-19]. In addition to the employment of a low cost-media for microalgae cultivation, wastewater treatment utilizing cyanobacteria and green microalgae also offers the advantage of the concomitant production of addedvalue products from the biomass obtained during the process. Microalgal biomass extracts can be used in the field of energy, aquaculture, or even as food supplements $[18,20,21]$. As stated before, the capacity of plants to remove HM and nutrients is also widely recognized [22].

Coupling this remediation ability with biomass production of some species, such as A. mauritanicus, it is possible to create a circular economy model to produce a sustainable source of renewable energy [23]. Associations of microalgae and plants are often visible in hydroponic systems, as microalgae provides oxygen for plant root respiration from photosynthesis [24]. Only a few studies have focused on coupling the remediation abilities of microalgae and plants; therefore, there is still much to understand about this combination and whether it would result in an improved treatment.

Recent studies on hydroponic systems coupling tomato plants with Chlorella infusionum, Chlorella vulgaris and Scenedesmus quadricauda [24,25] have reported a growthpromoting effect on all the involved organisms when co-cultivating. Furthermore, higher nutrient removal efficiency was also reported [15] for a co-cultivation of tomato plants and a mixed consortium of microalgae consisting mainly of Chlorella sp., along with Scenedesmus sp., Synechocystis sp. and Spirulina sp. compared to monoculture controls.

The aim of this work was to assess the feasibility of a combined approach using the green microalga Desmodesmus sp. and/or the cyanobacterium Nostoc sp. coupled with the hemicryptophyte $A$. mauritanicus for bioremediation of polluted waters with an excess of nutrients (nitrogen and phosphorus) and HM (copper and nickel).

\section{Results}

The water used as a culture medium in the present work was collected in the Fosso del Cavaliere river. This waterbody is monitored by the University of Rome Tor Vergata as it is 
located on the campus, and it is very polluted because it crosses a densely populated urban area and an industrial site. However, $\mathrm{Cu}$ and $\mathrm{Ni}$ were added, either alone or in combination because, despite its pollution, the water of the Fosso del Cavaliere was fortunately free of HM. Pre-treatment of the water involved filtration to remove any suspended solids and particulates that were naturally present.

\subsection{Preliminary Experiments with Microalgae}

The growth rates of Desmodesmus sp. and Nostoc sp. were significantly reduced in water containing $\mathrm{Cu}$ and the mixture of metals $(\mu<0.01 ; p<0.05)$ compared to the control ( $\mu=0.091$ and 0.087 for Desmodesmus sp. and Nostoc sp., respectively). The chlorophyll $a$ (Chl a) content in the control cultures of Desmodesmus sp. was more than 10-times higher than the cultures containing $\mathrm{Cu}\left(3.887 \pm 0.235\right.$ and $0.086 \pm 0.03 \mu \mathrm{g} \mathrm{mL} \mathrm{L}^{-1}$, respectively) after seven days (Figure 1a).
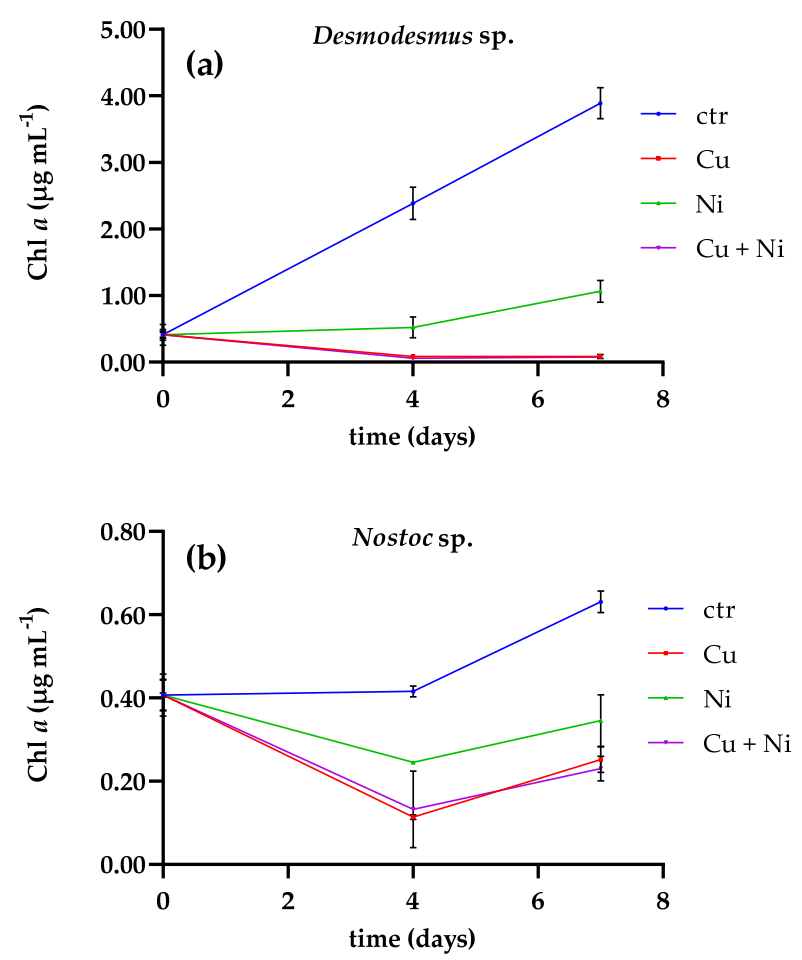

Figure 1. Time courses of the Chl a content (expressed in $\mu \mathrm{g} \mathrm{mL}^{-1}$ ) in (a) Desmodesmus sp. and (b) Nostoc sp. in the absence (ctr) or presence of $\mathrm{Cu}, \mathrm{Ni}$ and the mix of the two metals. Data are the mean values \pm standard deviations ( $p<0.05$ vs. control).

In water containing a mixture of the two metals, the $\mathrm{Chl} a$ concentration decreased from $0.411 \pm 0.077 \mu \mathrm{g} \mathrm{mL}^{-1}$ (day 0) to $0.079 \pm 0.001 \mu \mathrm{g} \mathrm{mL}^{-1}$ (day 7), while those containing only Ni were the less affected, with a Chl $a$ content of $1.065 \pm 0.164 \mu \mathrm{g} \mathrm{mL} \mathrm{m}^{-1}$ at day 7. Similar to Desmodesmus sp., the growth of Nostoc sp. was more affected by $\mathrm{Cu}$ than $\mathrm{Ni}(p<0.001)$. The $\mathrm{Chl} a$ content in the culture of Nostoc sp. exposed to $\mathrm{Cu}$ decreased from $0.406 \pm 0.051 \mu \mathrm{g} \mathrm{mL}^{-1}$ to $0.250 \pm 0.031 \mu \mathrm{g} \mathrm{mL}^{-1}$ (day 7). A decreasing trend was also shown in presence of both metals, with a final Chl $a$ concentration of $0.230 \pm 0.029 \mu \mathrm{g} \mathrm{mL}^{-1}$ (Figure 1b).

The $\mathrm{N}$ and $\mathrm{P}$ removal efficiencies (Figure 2) showed that the presence of metals reduced the nutrient removal capacities of both Desmodesmus sp. and Nostoc sp. However, the green microalga maintained some removal ability, although the results obtained in cultures grown in presence of metals were significantly lower than the controls $(p<0.001)$. 

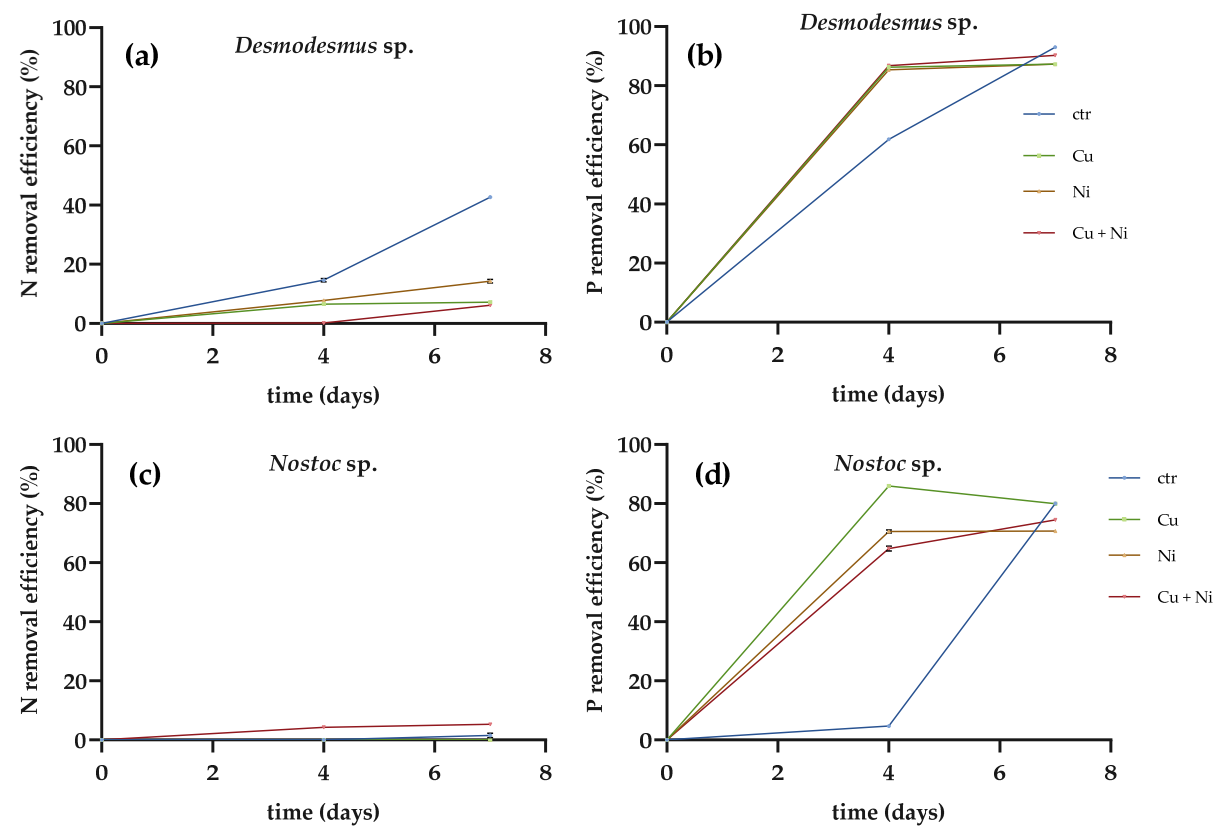

Figure 2. Removal efficiencies (\%) of $\mathrm{N}$ and $\mathrm{P}$ by (a,b) Desmodesmus sp. and (c,d) Nostoc sp. in control cultures and in the presence of $\mathrm{Cu}, \mathrm{Ni}$ and the mix of the two metals (data are the mean values \pm standard deviations; differences were considered significant for $p<0.05$, two-way ANOVA).

$\mathrm{N}$ removal by Desmodesmus sp. (Figure 2a) decreased from $44 \%$ (control) to $5 \%$ in the presence of $\mathrm{Cu}, 13 \%$ in the presence of $\mathrm{Ni}$ and $8 \%$ with both metals. P removal (Figure $2 \mathrm{~b}$ ) was decreased from $75 \%$ (control) to $46 \%$ in $\mathrm{Cu}$ and $49 \%$ in $\mathrm{Ni}$ and $57 \%$ in both metals. Nostoc sp. had a low $\mathrm{N}$ removal ability (Figure 2c) under all conditions, while its $\mathrm{P}$ removal capacity (Figure $2 \mathrm{~d}$ ) was more affected by $\mathrm{Ni}$ than $\mathrm{Cu}(p<0.001)$.

The metal removal capacity (Table 1) was also evaluated and showed that, in seven days, Desmodesmus sp. had removed $67 \%$ of the initial $\mathrm{Cu}$, resulting in a final concentration of $0.37 \mathrm{mg} \mathrm{L}^{-1}$. Nostoc sp. was unable to remove $\mathrm{Cu}$ from the water. Desmodesmus sp. was highly effective at removing $\mathrm{Ni}$, with values more than 10 times those of Nostoc sp. (Table 1). In solution with both metals $\left(0.89 \mathrm{mg} \mathrm{L}^{-1} \mathrm{Cu}\right.$ and $\left.1.76 \mathrm{mg} \mathrm{L}^{-1} \mathrm{Ni}\right)$, Desmodesmus sp. exhibited the highest removals for $\mathrm{Cu}(57 \%)$ and $\mathrm{Ni}(30 \%)$, with a residual concentration of 0.38 and $1.22 \mathrm{mg} \mathrm{L}^{-1}$, respectively. Nostoc sp. showed a Cu removal of $28 \%$ (residual content of $0.64 \mathrm{mg} \mathrm{L}^{-1}$ ) and a Ni removal of $11 \%$ (residual concentration of $1.56 \mathrm{mg} \mathrm{L}^{-1}$ ).

Table 1. Metal removal efficiencies of Desmodesmus sp. and Nostoc sp. evaluated in Test 1, after 7 days of metal treatment (data are the mean values of triplicates), where $\mathrm{C}_{\mathrm{f}}\left(\mathrm{mg} \mathrm{L}^{-1}\right)$ represents the final concentration (data are the mean values \pm standard deviations) and Removal (\%) the removal efficiency of metal present in solution (data are the mean values \pm standard deviations; differences were considered significant for $p<0.05$, two-way ANOVA).

\begin{tabular}{|c|c|c|c|c|c|c|c|c|}
\hline & \multicolumn{2}{|c|}{$\begin{array}{l}\text { Initial }[\mathrm{Cu}] \\
1.15 \mathrm{mg} \mathrm{L}^{-1}\end{array}$} & \multicolumn{2}{|c|}{$\begin{array}{l}\text { Initial [Ni] } \\
1.86 \mathrm{mg} \mathrm{L}^{-1}\end{array}$} & \multicolumn{4}{|c|}{$\begin{array}{c}\text { Mix } \\
0.89 \mathrm{mgCu} \mathrm{L}^{-1}+1.76 \mathrm{mgNi} \mathrm{L}^{-1}\end{array}$} \\
\hline & \multirow[t]{2}{*}{$\begin{array}{c}\mathrm{C}_{\mathrm{f}} \\
\left(\mathrm{mg} \mathrm{L}^{-1}\right)\end{array}$} & \multirow[t]{2}{*}{$\begin{array}{c}\text { Removal } \\
(\%)\end{array}$} & \multirow[t]{2}{*}{$\begin{array}{c}\mathrm{C}_{\mathrm{f}} \\
\left(\mathrm{mg} \mathrm{L}^{-1}\right)\end{array}$} & \multirow[t]{2}{*}{$\begin{array}{l}\text { Removal } \\
(\%)\end{array}$} & \multicolumn{2}{|c|}{$\begin{array}{c}\mathrm{C}_{\mathrm{f}} \\
\left(\mathrm{mg} \mathrm{L}^{-1}\right)\end{array}$} & \multicolumn{2}{|c|}{$\begin{array}{c}\text { Removal } \\
(\%)\end{array}$} \\
\hline & & & & & $\mathrm{Cu}$ & $\mathrm{Ni}$ & $\mathrm{Cu}$ & $\mathrm{Ni}$ \\
\hline Desmodesmus sp. & $0.37 \pm 0.04$ & $67 \%$ & $0.33 \pm 0.07$ & $82 \%$ & $0.38 \pm 0.09$ & $1.22 \pm 0.31$ & $57 \%$ & $30 \%$ \\
\hline Nostoc sp. & $1.70 \pm 0.41$ & n.d. & $0.73 \pm 0.09$ & $61 \%$ & $0.63 \pm 0.03$ & $1.56 \pm 0.19$ & $28 \%$ & $11 \%$ \\
\hline
\end{tabular}

\subsection{Sequential Tests A. mauritanicus/Desmodesmus sp.}

Desmodesmus sp., due to its metal resistance and uptake capacity of both nutrients and metals, was selected for a sequential test with A. mauritanicus. Preliminary tests 
established that $A$. mauritanicus and Desmodesmus sp. would not grow together because when A. mauritanicus plants were incubated in combination with Desmodesmus sp., the microalgae attached to the plant roots, and the plant leaves showed signs of bleaching; therefore, we decided to carry out a sequential test. First, A. mauritanicus was incubated in the test water for seven days, followed by a seven-day incubation with Desmodesmus sp. (a total of 14 days). The initial total $\mathrm{N}$ and total $\mathrm{P}$ concentrations were different from test 1 , as the water was sampled on different occasions. A. mauritanicus showed no signs of stress in the presence of the tested concentrations of metal, and both the quantities of chlorophyll and their morphology did not change compared to the control (data not shown).

As in the first test, the results obtained (Figure 3) showed that the presence of metals affected the nutrient removal efficiencies of both Desmodesmus sp. and A. mauritanicus as single species and in the sequential approach. In the presence of $\mathrm{Cu}$ and both metals, the $\mathrm{N}$ removal efficiency by A. mauritanicus/Desmodesmus sp. was less than $7 \%$, while, in the presence of $\mathrm{Ni}$, the $\mathrm{N}$ removal efficiency was $59 \%$ with a residual content of $3.01 \mathrm{mg} \mathrm{L}^{-1}$ after 14 days (Figure 3a). The $\mathrm{N}$ removal was $70 \%$ when grown in the absence of metals (control). In the presence of $\mathrm{Cu}$ and $\mathrm{Ni}$, the $\mathrm{P}$ removal was $39 \%$ and $36 \%$, respectively (Figure $3 b$ ), which were not statistically different $(p>0.05)$, and was only $13 \%$ in the combined metal solution (five-times lower than in the control cultures).
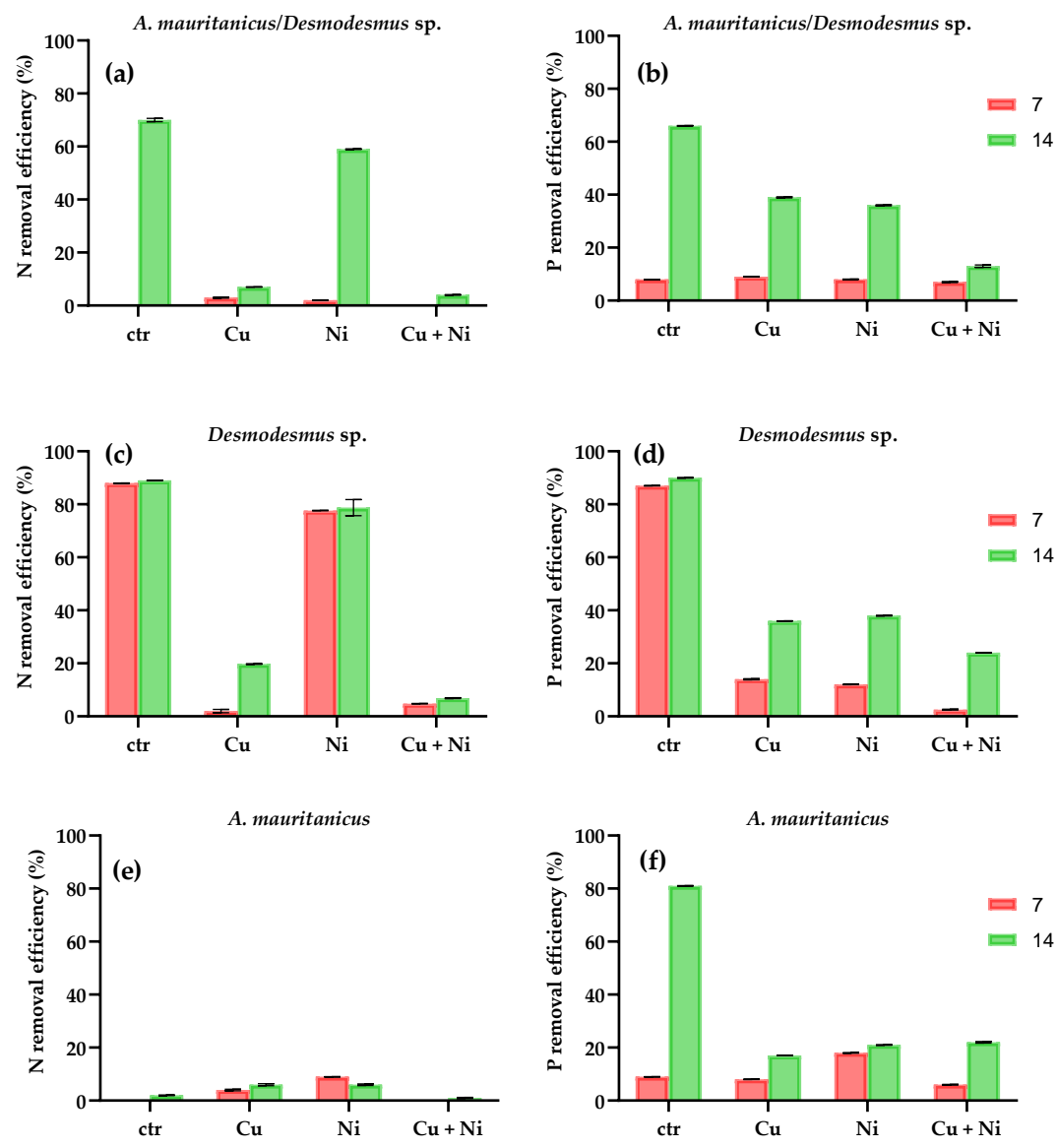

Figure 3. $\mathrm{N}$ and $\mathrm{P}$ removal efficiencies (expressed as percentage after 7 and 14 days of treatment) of Test 2 in: (a,b) A. mauritanicus/Desmodesmus sp., (c,d) Desmodesmus sp. and (e,f) A. mauritanicus. (Data are the mean values of triplicates \pm standard deviations). Multiple comparisons test was used to analyze data along with two-way ANOVA with Tukey's. Differences were considered significant at $p<0.05$.

There were no significant differences between the sequential approach $A$. mauritanicus/Desmodesmus sp. and single species control cultures of A. mauritanicus ( $p>0.05$ and $p=0.9069$ ). In the single-species test, Desmodesmus sp. Demonstrated a greater ability to 
remove $\mathrm{N}$ and $\mathrm{P}$ over $A$. mauritanicus $(p<0.0001)$. The $\mathrm{N}$ removal efficiency of Desmodesmus sp. alone (Figure 3c) was significantly lower in media containing $\mathrm{Cu}$ compared with $\mathrm{Ni}$ : after 14 days, $\mathrm{N}$ removal in the presence of $\mathrm{Cu}$ was $21 \%$ and $79 \%$ in Ni cultures and only $4 \%$ in the presence of both metals.

Compared to the $90 \%$ of $\mathrm{P}$ removal in control cultures, the $\mathrm{P}$ removal efficiency of Desmodesmus sp. was reduced in the presence of metals: the effect of single metals was similar (36\% of $\mathrm{P}$ removal in presence of $\mathrm{Cu}$ and $38 \%$ for $\mathrm{Ni}$ ), while the presence of both metals reduced the P removal at only $24 \%$ (Figure $3 \mathrm{~d}$ ). After the 14 -day incubation, the $\mathrm{N}$ removal efficiency of $A$. mauritanicus was around $6 \%$ in all the conditions tested (Figure $3 e$ ). The $\mathrm{P}$ removal efficiency after 14 days was $17 \%$ in the presence of $\mathrm{Cu}, 21 \%$ in the presence of $\mathrm{Ni}$ and $22 \%$ for both metals. The P removal efficiencies of $A$. mauritanicus control reached the $90 \%$ after 14 days (Figure $3 \mathrm{f}$ ).

The A. mauritanicus / Desmodesmus sp. results from Test 2 showed that, after 14 days, the metal removal efficiencies were $74 \%$ for $\mathrm{Cu}$ (giving a residual concentration of $0.29 \mathrm{mg} \mathrm{L}^{-1}$ ) and $85 \%$ for $\mathrm{Ni}$ (giving a residual concentration of $0.29 \mathrm{mg} \mathrm{L}^{-1}$ ) (Figure $4 \mathrm{a}$ ). The $\mathrm{Cu}$ removal in the bi-metal solution was $59 \%$ with a residual concentration of $0.36 \mathrm{mg} \mathrm{L}^{-1}$ (Figure $4 \mathrm{~d}$ ). The removal efficiencies after 14 days in single species experiments were significantly higher for Desmodesmus sp. Than for the combination of A. mauritanicus / Desmodesmus sp. and $A$. mauritanicus alone $(p<0.001$ and $p=0.00075)$. Desmodesmus sp. (Figure $4 b)$ exhibited the highest $\mathrm{Cu}$ removal efficiency after 7 days (77\%) with a residual content of $0.27 \mathrm{mg} \mathrm{L}^{-1}$; however, after 14 days, the overall $\mathrm{Cu}$ removal was reduced to $53 \%$.
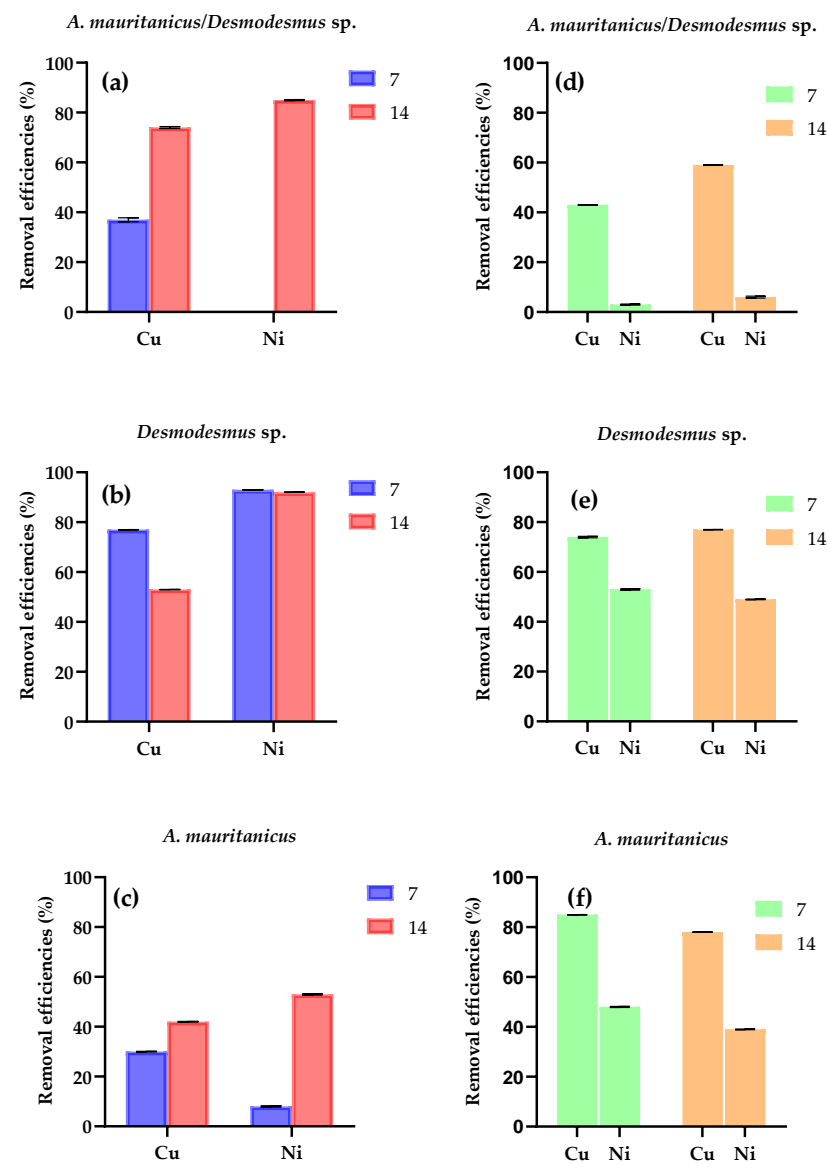

Figure 4. $\mathrm{Cu}$ and Ni removal efficiencies of sequential tests of $(\mathbf{a}-\mathbf{c})$ single metal solution and $(\mathbf{d}-\mathbf{f})$, mix solution of $\mathrm{cu}$ and Ni. Removal efficiency (expressed as percentage, \%) reported after 7 and 14 days of treatment (data are the mean values of triplicates \pm standard deviations). A multiple comparisons test was used to analyze data along with two-way ANOVA with Tukey's. Differences were considered significant at $p<0.05$. 
This might be explained by a release of $\mathrm{Cu}$ in the aqueous medium by the green microalga, due to the reversible metal ion adsorption on the cell walls of microalgae [26]. The Ni removal efficiency of Desmodesmus sp. was higher than A. mauritanicus, showing a $93 \%$ of removal after 7 days that remained stable until the end of the test, while the A. mauritanicus removed $53 \%$ of the medium Ni, by day 14 (Figure $4 \mathrm{c}$ ). In the bi-metal solution, the $\mathrm{Cu}$ and $\mathrm{Ni}$ removal by single cultures of Desmodesmus sp. and A. mauritanicus was always higher than that measured in the combined sequential system (Figure $4 \mathrm{e}, \mathrm{f}$ ).

\section{Discussion}

The present work was a preliminary bioremediation test to evaluate the nutrient and metal removal capacity of two strains of microalgae, a metallophyte and a sequential algahigher plant treatment. Few studies have focused on coupling the wastewater remediation abilities of plants and microalgae to understand if these combinations could improve treatment potentials [27]. According to the European Water Framework Directive (2000/60 EC) before discharging into water bodies, the total nitrogen (TN) and total phosphorus (TP) concentrations must be reduced to $15 \mathrm{mg} \mathrm{L}^{-1}$ and $2 \mathrm{mg} \mathrm{L}^{-1}$ for agglomerations of 10-100 thousand population equivalents (PE). For more sensitive areas (more than 100 thousand $\mathrm{PE}$ ), the TN levels must be reduced to $10 \mathrm{mg} \mathrm{L}^{-1}$ and the TP must not exceed $1 \mathrm{mg} \mathrm{L}^{-1}$.

A preliminary test was carried out to choose between the microalga, Desmodesmus sp., and a cyanobacterium, Nostoc sp., based on their metal and nutrient uptake capacity, to use in combination with $A$. mauritanicus. The growth rates of the green microalga and the cyanobacterium were significantly reduced by the presence of metals $(p<0.05)$, especially in the presence of $\mathrm{Cu}$, either alone or in combination with $\mathrm{Ni}$.

The stress caused by the metals was revealed by the final $\mathrm{Chl} a$ content, which was 97\% lower in the $\mathrm{Cu}$ culture compared to the control. Adverse effects of $\mathrm{Cu}$ and $\mathrm{Ni}$ on the growth rate of Desmodesmus sp. were previously reported by Rugnini et al. [28], however, to a lesser extent (a reduction of $85 \%$ of $\mathrm{Chl} a$ at $11.9 \mathrm{mg} \mathrm{Cu} \mathrm{L}^{-1}$ ). Even if microalgae showed a drastic change in vitality, they were still able to remove metals. Metal ions are taken up by microalgal biomass in a two-stage process: an adsorption and bioaccumulation process. At first, the metal ions are passively adsorbed on the cell surface (of both living and non-living biomass) in a few seconds or minutes; then, the ions are transported slowly inside the cell membrane and are accumulated intracellularly. Bioaccumulation occurs only in living cells $[18,26]$.

Thus, even if the microalgae vitality is reduced, they are still able to remove metals from solution by passive adsorption, and therefore the removal of $\mathrm{Cu}$ and $\mathrm{Ni}$ in Desmodesmus sp. was higher than $50 \%$ in this culture conditions. On the other hand, the lower growth rate of Desmodesmus sp. is the likely explanation of the lower $\mathrm{N}$ and P removal capacities obtained in cultures. The metal toxicity effect on growth could also explain why Nostoc sp. had even lower $\mathrm{N}$ and $\mathrm{P}$ removal efficiencies in the presence of metal. Similar findings of an inhibitory Ni effect limiting the nutrient uptake capacity of $C$. vulgaris were previously determined [29].

The $\mathrm{N}$ removal efficiency of $C$. vulgaris was affected at only high Ni concentrations, and $\mathrm{P}$ removal was far more sensitive to Ni. However, in this experiment, the effect of metals on $\mathrm{P}$ removal was lower than that on $\mathrm{N}$ removal. Previous studies, on the other hand, showed for Desmodesmus sp., a P removal efficiency between $94 \%$ and $100 \%$ in the presence of $\mathrm{Cu}$ and $\mathrm{Ni}$ singularly or in combination, and a strain of Chlorella sp. [30] exposed to different metals ( $\mathrm{Cr}, \mathrm{Cu}, \mathrm{Mn}, \mathrm{Zn}, \mathrm{Fe}, \mathrm{Na}$ and $\mathrm{K}$ ) showed no effect on the nutrient uptake. Due to the significant effect of metals on the nutrient uptake rates for Nostoc sp., we decided to conduct the sequential study using Desmodesmus sp. with A. mauritanicus. As observed in test 1 , the presence of metals significantly reduced the nutrient removal efficiency, in particular $\mathrm{N}(p<0.05)$.

The highest $\mathrm{N}$ removal in the $A$. mauritanicus/Desmodesmus sp. test occurred in the presence of $\mathrm{Ni}(59 \%)$, out of which only $2 \%$ was removed until day 7 by $A$. mauritanicus. Although A. mauritanicus is considered a metallophyte, it appears to be sensitive to Ni. 
Many studies have shown that HM interfere with the physiological processes of plants, one of which is nutrient absorption [31], in Arabidopsis thaliana L. [32] and Silene vulgaris (Moench) Garcke [33], Cu was shown to reduce the uptake of nitrogen, among other nutrients. Two-way ANOVA tests showed that, apart from the microalga and the plant, the $\mathrm{N}$ removal efficiency was dependent on which metal was present $(p<0.05)$ while the $\mathrm{P}$ removal was indifferent $(p>0.05)$.

The highest $\mathrm{Cu}$ removal efficiency $(74 \%)$ was obtained in the sequential treatment of A. mauritanicus/Desmodesmus sp., while the single species controls showed removals of less than $53 \%$. A similar result was shown for a consortium between Pistia stratiotes and Ankistrodesmus sp. [34], which showed a higher efficiency than the results reported in our work, with a Cu removal of $90 \%$ after $72 \mathrm{~h}$. Therefore, in this case, the sequential treatment A. mauritanicus/Desmodesmus sp. was more effective than the single species removing $\mathrm{Cu}$. On the contrary, in the presence of $\mathrm{Ni}$, the sequential test efficiency was lower than the single species.

In this study, the Ni removals were higher than those reported by Rugnini et al. [28] (12 days, initial Ni concentration of $1.9 \mathrm{mg} \mathrm{L}^{-1}$, removal rates of $30 \%$ for Desmodesmus sp. and $6 \%$ for Chlorella sp.). However, the same preferential cell-binding affinity of $\mathrm{Cu}$ over $\mathrm{Ni}$ in multi-metal solutions was reported. This preference could be explained by the stronger binding strength and larger ionic radius of $\mathrm{Cu}$ compared to $\mathrm{Ni}$, as these will increase the covalent interaction between the metal ion and the ligands-in particular, the carboxylate groups of algal cell walls [18].

In the bi-metal solution tests, the single species resulted as more efficient compared to the sequential test $(p<0.05)$. Several studies have been performed to determine the remediation ability of microalgae and plants individually and yet there is a scarcity of information on the combined effects of plants/microalgae for pollutant removal. Numerous studies have reported on the algistatic or algicidal effects of plant allelochemicals [35], and some showed allelopathic substances of terrestrial plants in aquatic systems.

Fifteen allelopathic substances in extracts of Cyperus alternifolius L. and Canna generalis L.H. Bailey \& E.Z. Bailey have been determined, most of which inhibited Microcystis aeruginosa growth [36], while aqueous extracts of rice straw [37] are effective algicides. This could explain the low removal efficiency observed in the sequential test plants/algae carried out in this study when compared to the control.

\section{Materials and Methods}

\subsection{Microalgal Strains}

The strains selected for this study were the green microalga Desmodesmus sp. VRUC281 and the cyanobacterium Nostoc sp. VRUC270 (Figure 5). Both strains were isolated from a secondary sedimentation tank of a municipal wastewater treatment plant (WWTP) and belong to the culture collection of the Tor Vergata Rome University Culture collection (VRUC) [38]. Stock cultures were grown in BG11 and BG11 0 culture media [39], in $175 \mathrm{~cm}^{2}$ aerated flasks, in a temperature and light controlled chamber at $18 \pm 2{ }^{\circ} \mathrm{C}$ and irradiance of $12 \pm 2 \mu \mathrm{mol}$ photons ${ }^{-1} \mathrm{~m}^{-2} \mathrm{~s}^{-1}$, with a light/dark cycle of $12: 12 \mathrm{~h}$.

(a)

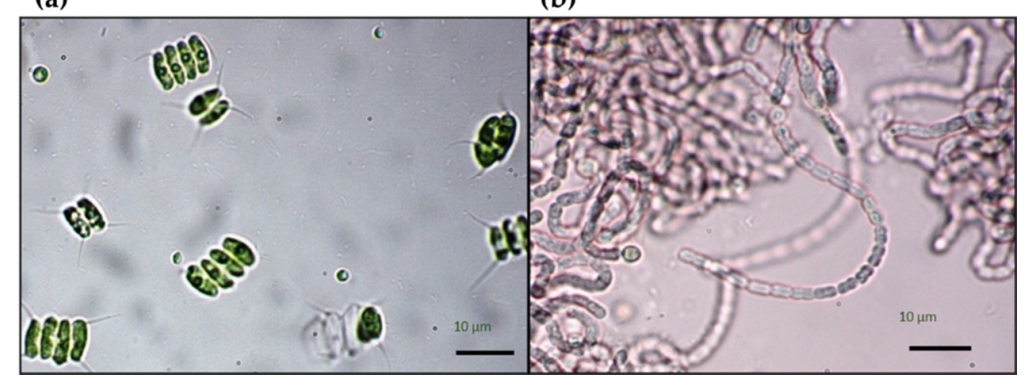

Figure 5. Light microscope (LM) images of the isolated strain of the (a) green microalga Desmodesmus sp. VRUC281 and (b) the cyanobacterium Nostoc sp. VRUC270 at $40 \times$. 


\subsection{Plant Materials}

Seeds were obtained from plants grown in the Botanic Gardens of the University of Rome Tor Vergata, where a pilot phytoremediation system of approximately $143 \mathrm{~m}^{2}$ was installed for field tests of the uptake and degradation capacity of A. mauritanicus. Caryopses were collected in October 2019 and were deprived of glume and lemma before use. Subsequently, they were stored at $4{ }^{\circ} \mathrm{C}$ to maintain the viability and to synchronize the germination (Figure 6). For the sterilization procedures, the caryopses were exposed to 70\% ethanol for $30 \mathrm{~s}$, washed three times with autoclaved distilled water, followed by treatment with $15 \%(w / v)$ sodium hypochlorite and two drops of TWEEN ${ }^{\circledR} 20$ (SIGMA-ALDRICH, St Louis, MO-USA), kept on a gyratory shaker at $110 \mathrm{rpm}$ for $1 \mathrm{~h}$ and then washed three times with sterile distilled water.

(a)

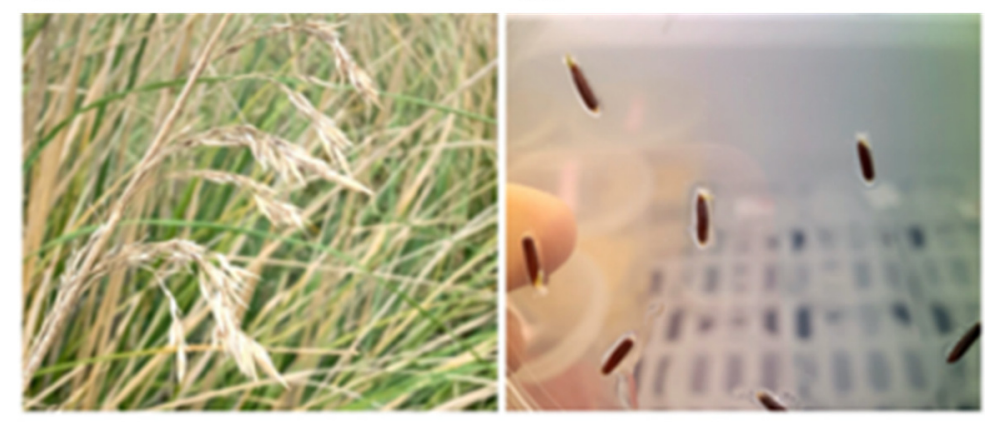

Figure 6. (a) Inflorescence of A. mauritanicus; and (b) in vitro sowing of $A$. mauritanicus kernels.

A. mauritanicus caryopses were placed on micro-perforated floating rafts, inside a propylene box $(90 \times 140 \mathrm{~mm})$, containing $250 \mathrm{~mL}$ of MS liquid medium [40] and $2 \%$ sucrose. The $\mathrm{pH}$ was adjusted to $5.6-5.8$ before autoclaving at $121^{\circ} \mathrm{C}$ for $20 \mathrm{~min}$. Cultures were incubated in a growth chamber at $25 \pm 2{ }^{\circ} \mathrm{C}$ under a $16 / 8 \mathrm{~h}$ light/dark-photoperiod by cool white led lamps at density of $30-40 \mu \mathrm{mol} \mathrm{m}^{-2} \mathrm{~s}^{-1}$. After four weeks, the plantlets were transferred to a new medium containing water of Fosso del Cavaliere river that had been previously membrane filtered (pore size 0.2 micron) and autoclaved. Before transfer, the roots were washed three times with distilled water.

\subsection{Preliminary Test with Microalgae}

In test 1, Desmodesmus sp. and Nostoc sp. strains were grown for seven days in water of Fosso del Cavaliere river (Rome, Italy, $41^{\circ} 50^{\prime} 55.2^{\prime \prime} \mathrm{N} 12^{\circ} 38^{\prime} 49.7^{\prime \prime} \mathrm{E}$ ), pre-filtered with a Millipore ${ }^{\circledR}$ Stericup ${ }^{\circledR}$ filtration system and supplemented with copper $(\mathrm{Cu})$, from copper sulphate $\left(\mathrm{CuSO}_{4} \cdot 5 \mathrm{H}_{2} \mathrm{O}\right.$, Sigma-Aldrich reagent grade) or nickel (Ni), from nickel sulphate $\left(\mathrm{NiSO}_{4} \cdot 7 \mathrm{H}_{2} \mathrm{O}\right.$, Sigma-Aldrich reagent grade), as single $\left(1.15 \mathrm{mg} \mathrm{Cu} \mathrm{L}^{-1}, 1.86 \mathrm{mg} \mathrm{Ni} \mathrm{L}^{-1}\right)$ or bi-metal solutions $\left(0.89 \mathrm{mg} \mathrm{Cu} \mathrm{L}^{-1}+1.76 \mathrm{mg} \mathrm{Ni} \mathrm{L}^{-1}\right)$. The $\mathrm{HM}$ concentrations used in the present work are the average of those detected in other metal polluted waterbodies we have studied. A control lacking both metals was also used. The growth was monitored through optical density (OD) and the Chl $a$ content immediately after the inoculum ( $\left.\mathrm{t}_{0}\right)$ and at days 4 and 7 .

\subsection{Sequential Test}

Sequential treatments were used because, when eight-weeks-old $A$. mauritanicus plants (ranging from 100 to $120 \mathrm{~mm}$ in height) were incubated in combination with Desmodesmus sp., after 7 days, the microalgae had attached to the plant roots, and the plant leaves showed signs of bleaching (data not shown). Thus, we decided to perform the second experiment (test 2) using a sequential approach. Hadiyanto et al. [41] employed aquatic plants, water hyacinth (Eichhornia crassipes) and water lily (Nymphaea sp.) as well as the cyanobacterium Spirulina sp. to reduce the COD and nutrient content in palm oil mill effluent. In the first 
stage, the authors employed plants (3-8 days) and then the microalgae (15 days). Thereby, we planned our experiment similarly.

During the first week (day 0 to 7), three plants of A. mauritanicus were grown in $250 \mathrm{~mL}$ solutions containing either $\mathrm{Cu}, \mathrm{Ni}$ or a combination of both metals at the same concentration of test 1 (Figure 7a). After 7 days, the plants were removed and an inoculum of $15 \mathrm{~mL}$ of the green microalga Desmodesmus sp. was added to the culture medium and left for another week (day 7 to 14) (Figure $7 \mathrm{~b}$ ). The nutrient and metal removal efficiencies were evaluated by collecting $25 \mathrm{~mL}$ for each treatment, which was repeated at the beginning of the experiment and at 7 and 14 days for $\mathrm{N}$ and $\mathrm{P}$ analysis, while another $50 \mathrm{~mL}$ was collected for metal analysis on the same days. Three replicates with five plants in each box were used for each treatment. The control cultures were A. mauritanicus and Desmodesmus sp. singularly and combined in the water of Fosso del Cavaliere river containing no $\mathrm{Cu}$ and Ni.

(a)

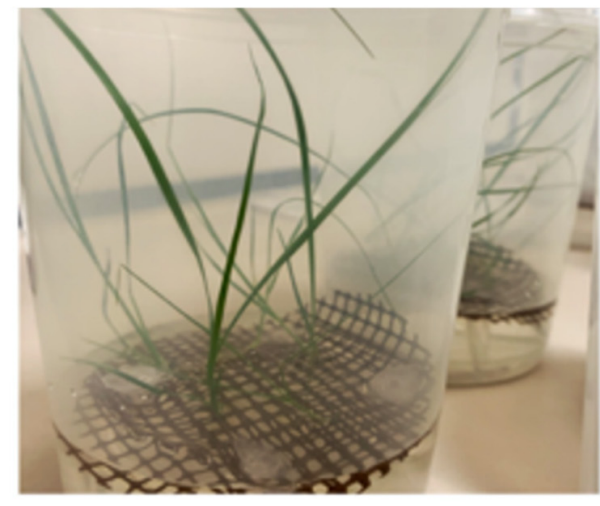

(b)

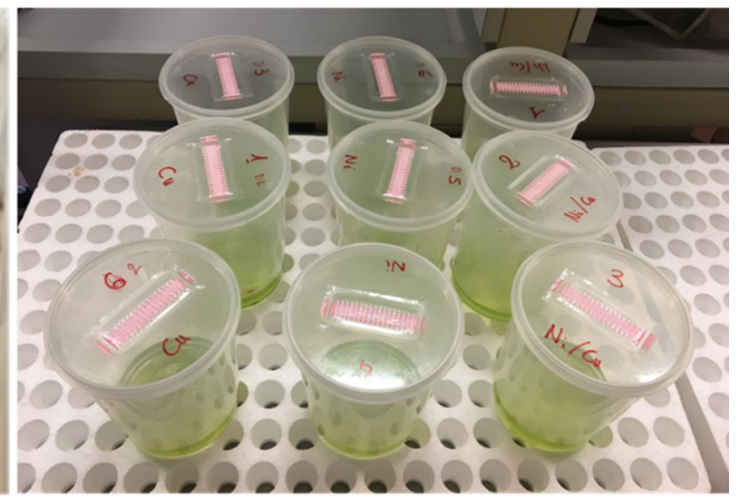

Figure 7. Sequential test employing (a) five plants of $A$. mauritanicus from day 0 to 7 and (b) Desmodesmus sp. from day 7 to 14 , to evaluate the N, P, Cu and Ni removal.

\subsection{Evaluation of Growth}

Culture growth was monitored by measuring the optical densities at $560\left(\mathrm{OD}_{560}\right)$ and $730 \mathrm{~nm}\left(\mathrm{OD}_{730}\right)$ with an ONDA-UV spectrophotometer for Desmodesmus sp. and Nostoc sp., respectively. The growth rates $(\mu)$ were calculated from a triplicate measure of OD of the cultures, according to Rugnini et al. [18].

The growth was also evaluated in terms of the variation in the chlorophyll $a$ content. Pigment extraction was performed according to Wellburn and Lichtenthaler [42] in methanol at $95 \%$. The Chl $a$ concentration was calculated as follows (Equation (1)):

$$
\operatorname{Chl}_{a}\left(\frac{\mu g}{m L}\right)=15.65 \times A_{666}-7.34 \times A_{653} .
$$

\subsection{Nutrient Analysis}

Due to the intrinsic variability of nitrogen $(\mathrm{N})$ and phosphorus $(\mathrm{P})$ concentration in the river of Fosso del Cavaliere, the TN and TP were evaluated at the beginning of each test. The $\mathrm{N}$ and $\mathrm{P}$ removal efficiencies were determined by detecting the residual concentrations in the media, after sample filtration with Whatman paper filters $(1.2 \mu \mathrm{m}$ pores). The removal efficiencies were also determined after 4 and 7 days according to Langer and Hendrix [43]. The N and P removal efficiencies were calculated using Equations (2) and (3):

$$
N_{\%}=\frac{N_{0}-N_{t}}{N_{0}}
$$

where $N_{0}$ is the initial concentration of $N$ and $N_{t}$ is the concentration of $N$ after $t$ days of cultivation $[31,32]$.

$$
P_{\%}=\frac{P_{0}-P_{t}}{P_{0}}
$$


where $P_{0}$ is the initial $P$ concentration and $P_{t}$ is the concentration of $P$ after $t$ days of cultivation.

\subsection{Metal Analysis}

The concentrations of $\mathrm{Cu}$ and $\mathrm{Ni}$ were analyzed by inductively coupled plasma atomic emission spectroscopy (ICP-OES). The $\mathrm{Cu}$ and $\mathrm{Ni}$ removal efficiencies were determined by detecting the residual concentrations in the media after $50 \mathrm{~mL}$ of sample filtration with Whatman paper filters ( $1.2 \mu \mathrm{m}$ pores) at days 4 and 7 . Before the analyses, the samples were acidified to $\mathrm{pH}<2$ with ultrapure nitric acid (APAT CNR IRSA 3010A Man 292003 + APAT CNR IRSA 3020 Man29 2003).

The $\mathrm{Cu}$ and Ni removal efficiencies (Removal, \%) were evaluated according to Zhou et al. [44] (Equation (4)):

$$
\text { Removal }=\frac{\left(C_{0}-C_{f}\right) \times 100}{C_{0}}
$$

where $C_{0}$ is the initial concentration of either $\mathrm{Cu}$ or $\mathrm{Ni}\left(\mathrm{mg} \mathrm{L}^{-1}\right)$ and $C_{f}$ is the final concentration. All experiments were performed in triplicates.

\subsection{Statistical Analysis}

All results are expressed as the mean $+/$ - standard deviation from three different replicates. Data were analyzed using the GraphPad Prism software, version 9.0.1 (San Diego, CA, USA). To compare the differences in the growth curves of Desmodesmus sp. and Nostoc sp. in the presence of metals (Figure 1), an unpaired $t$-test was used. To analyze the influence of metals in the $\mathrm{N}$ and $\mathrm{P}$ removal efficiencies (Figure 2) a two-way ANOVA with Tukey's multiple comparisons test was employed. A multiple comparisons test was used to analyze the data of test 2 along with two-way ANOVA with Tukey's (Figures 3 and 4 ). Differences were considered significant at $p<0.05$.

\section{Conclusions}

Both microalgae and plants exhibited a high potential for the remediation of polluted waters from excess nutrients and metals. The present work evaluated the feasibility of a sequential approach exploiting the hemicryptophyte $A$. mauritanicus, the green microalga Desmodesmus sp. VRUC281 and the cyanobacterium Nostoc sp. VRUC270 for N, P and metal $(\mathrm{Cu}$ and $\mathrm{Ni}$ ) removal. The presence of metals caused a reduction in growth and in the nutrient removal ability.

Nostoc sp. was more sensitive to the presence of metals; therefore, Desmodesmus sp. was chosen for sequential tests using plants and microalgae. However, the green microalga alone was able to remove more nutrients compared to the sequential plant/microalga treatment. The sequential approach had a higher metal removal capacity in the presence of singular metals: up to $74 \%$ for $\mathrm{Cu}$ and $85 \%$ for $\mathrm{Ni}$ in 14 days. In the bi-metal solutions, the removal rates were lower with a preferential affinity for $\mathrm{Cu}$ over $\mathrm{Ni}(43 \%$ for $\mathrm{Cu}$ and $6 \%$ for $\mathrm{Ni}$ ).

The removal rates were higher in the single species controls, indicating a negative effect possibly as a result of allelopathic phenomena between plants and algae. The plant and the microalga selected for this study presented better removal abilities for nutrients and metals when used singularly compared to the sequential approach. Further studies are necessary to define the mechanisms underlying these results as well as to exploit new combination of plants and microalgae species.

Author Contributions: Conceptualization, R.B., L.R. and L.B.; methodology, R.B., L.R., S.M., F.S., E.L.R., A.C. and L.B.; investigation, R.B., L.R., S.M., F.S., E.L.R. and L.B.; writing-original draft preparation, R.B., L.R., S.M. and L.B.; writing—review and editing, R.B., L.R., S.M., F.S., E.L.R., A.C. and L.B.; supervision, A.C. and L.B.; project administration, R.B., L.R. and L.B.; funding acquisition, L.B. All authors have read and agreed to the published version of the manuscript. 
Funding: This work was partially funding by the grant "Mission Sustainability 2017"-University of Rome Tor Vergata.

Acknowledgments: The authors thanks Neil T. W. Ellwood for the English revision and his helpful comments.

Conflicts of Interest: The funders had no role in the design of the study; in the collection, analyses, or interpretation of data; in the writing of the manuscript, or in the decision to publish the results.

\section{References}

1. Salt, D.E.; Smith, R.D.; Raskin, I. Phytoremediation. Annu. Rev. Plant. Physiol. 1998, 49, 643-668. [CrossRef] [PubMed]

2. Cunningham, S.D.; Anderson, T.A.; Schwab, P.; Hsu, F.C. Phytoremediation of soils contaminated with organic pollutants. Adv. Agron. 1996, 56, 55-114.

3. Meagher, R.B. Phytoremediation of toxic elemental and organic pollutants. Curr. Opin. Plant. Biol. 2000, 3, 153-162. [CrossRef]

4. Clemens, S.; Palmgreen, M.G.; Kraemer, U. A long way ahead: Understanding and engineering plant metal accumulation. Trends Plant. Sci. 2002, 7, 309-315. [CrossRef]

5. Karimi, N.; Ghaderian, S.M.; Raab, A.; Feldmann, J.; Meharg, A.A. An arsenic-accumulating, hypertolerant brassica, Isatis cappadocica. New Phytol. 2009, 184, 41-47. [CrossRef] [PubMed]

6. Banuelos, G.S.; Meek, D.W. Selenium accumulation in selected vegetables. J. Plant. Nutr. 1989, 12, 1255-1272. [CrossRef]

7. Raskin, I.; Smith, R.D.; Salt, D.E. Phytoremediation of metals: Using plants to remove pollutants from the environment. Curr. Opin. Biotechnol. 1997, 8, 221-226. [CrossRef]

8. Pignatti, S. La Flora d'Italia; Edagricole: Bologna, Italy, 1984; p. 3.

9. Mingo, A.; Mazzoleni, S. Ecophysiology of five Mediterranean perennial grasses: I) Effects of shade, water stress and defoliation on growth and allocation. Plant. Biosyst. 1997, 131, 207-215. [CrossRef]

10. Cuellar-Bermudez, S.P.; Aleman-Nava, G.S.; Chandra, R.; Garcia-Perez, S.; Contreras-Angulo, J.R.; Markou, G.; Muylaert, K.; Rittmann, B.E.; Parra-Saldivar, R. Nutrient utilization and contaminants removal. A review of two approaches of algae and cyanobacteria in wastewater. Algal Res. 2017, 24, 438-449. [CrossRef]

11. Ahmad, S.; Pandey, A.; Pathak, V.V.; Tyagi, V.V.; Kothari, R. Phycoremediation: Algae as Eco-friendly Tools for the Removal of Heavy Metals from Wastewaters. In Bioremediation of Industrial Waste for Environmental Safety; Springer: Singapore, 2020; pp. 53-76.

12. Abdel-Raouf, N.; Al-Homaidan, A.A.; Ibrahem, I.B.M. Microalgae and wastewater treatment. Saudi J. Aquat. Sci. 2012, 19, 257-275. [CrossRef] [PubMed]

13. Jais, N.M.; Mohamed, R.M.S.R.; Al-Gheethi, A.A.; Amir Hashim, M.K. The dual roles of phycoremediation of wet market wastewater for nutrients and heavy metals removal and microalgae biomass production. Clean Technol. Environ. Policy 2017, 19, 37-52. [CrossRef]

14. Oswald, W.J.; Gotaas, H.B. Photosynthesis in sewage treatment. Trans. Am. Soc. Civ. Eng. 1957, 122, 73-105. [CrossRef]

15. Pacheco, D.; Rocha, A.C.; Pereira, L.; Verdelhos, T. Microalgae Water Bioremediation: Trends and Hot Topics. Appl. Sci. 2020, 10, 1886. [CrossRef]

16. Gao, F.; Li, C.; Yang, Z.H.; Zeng, G.M.; Mu, J.; Liu, M.; Cui, W. Removal of nutrients, organic matter, and metal from domestic secondary effluent through microalgae cultivation in a membrane photobioreactor. J. Chem. Technol. Biotechnol. 2016, 91, 2713-2719. [CrossRef]

17. Matamoros, V.; Gutiérrez, R.; Ferrer, I.; García, J.; Bayona, J.M. Capability of microalgae-based wastewater treatment systems to remove emerging organic contaminants: A pilot-scale study. J. Hazard. Mater. 2015, 288, 34-42. [CrossRef] [PubMed]

18. Rugnini, L.; Costa, G.; Congestri, R.; Antonaroli, S.; Sanità di Toppi, L.; Bruno, L. Phosphorus and metal removal combined with lipid production by the green microalga Desmodesmus sp.: An integrated approach. Plant. Physiol. Biochem. 2018, 125, 45-51. [CrossRef]

19. Shahid, A.; Malik, S.; Zhu, H.; Xu, J.; Nawaz, M.Z.; Nawaz, S.; Alam, M.A.; Mehmood, M.A. Cultivating microalgae in wastewater for biomass production, pollutant removal, and atmospheric carbon mitigation; a review. Sci. Total Environ. 2020, 135303. [CrossRef] [PubMed]

20. Bruno, L.; Di Pippo, F.; Antonaroli, S.; Gismondi, A.; Valentini, C.; Albertano, P. Characterization for biofilm-forming cyanobacteria for biomass and lipid production. J. Appl. Microbiool. 2012, 113, 1052-1064. [CrossRef] [PubMed]

21. Gismondi, A.; Di Pippo, F.; Bruno, L.; Antonaroli, S.; Congestri, R. Phosphorus removal coupled to bioenergy production by three cyanobacterial isolates in a biofilm dynamic growth system. Int. J. Phycol. 2016. [CrossRef]

22. Ashraf, S.; Ali, Q.; Zahir, Z.A.; Ashraf, S.; Asghar, H.N. Phytoremediation: Environmentally sustainable way for reclamation of heavy metal polluted soils. Ecotoxicol. Environ. Saf. 2019, 15, 714-727. [CrossRef]

23. Codignole Luz, F.; Cordiner, S.; Manni, A.; Mulone, V.; Rocco, V.; Braglia, R.; Canini, A. Ampelodesmos mauritanicus pyrolysis biochar in anaerobic digestion process: Evaluation of the biogas yield. Energy 2018, 161, 663-669.

24. Zhang, J.; Wang, X.; Zhou, Q. Co-cultivation of Chlorella spp. and tomato in a hydroponic system. Biomass Bioenergy 2017, 97, 132-138. [CrossRef] 
25. Barone, V.; Puglisi, I.; Fragalà, F.; Lo Piero, A.R.; Giuffrida, F.; Baglieri, A. Novel bioprocess for the cultivation of microalgae in hydroponic growing system of tomato plants. J. Appl. Phycol. 2019, 31, 465-470. [CrossRef]

26. Kumar, K.S.; Dahms, H.U.; Won, E.J.; Lee, J.S.; Shin, K.H. Microalgae-A promising tool for heavy metal remediation. Ecotoxicol. Environ. Saf. 2014, 113, 329-352. [CrossRef] [PubMed]

27. Supraja, K.V.; Behera, B.; Balasubramanian, P. Performance Evaluation of Hydroponic System for Co-cultivation of Microalgae and Tomato plant. J. Clean Prod. 2020, 122823. [CrossRef]

28. Rugnini, L.; Costa, G.; Congestri, R.; Bruno, L. Testing of two different strains of green microalgae for Cu and Ni removal from aqueous media. Sci. Total Environ. 2017, 601-602, 959-967. [CrossRef] [PubMed]

29. Santos, F.M.; Mazur, L.P.; Mayer, D.A.; Vilar, V.J.P.; Pires, J.C.M. Inhibition effect of zinc, cadmium, and nickel ions in microalgal growth and nutrient uptake from water: An experimental approach. Chem. Eng. J. 2019, 366, 358-367. [CrossRef]

30. Liu, Y.; Zhan, J.; Hong, Y. Effects of metal ions on the cultivation of an oleaginous microalga Chlorella sp. Environ. Sci. Pollut. Res. 2017, 24, 26594-26604. [CrossRef] [PubMed]

31. Nagajyoti, P.C.; Lee, K.D.; Sreekanth, T.V.M. Heavy metals, occurrence and toxicity for plants: A review. Environ. Chem. Lett. 2010, 8, 199-216. [CrossRef]

32. Hippler, F.W.; Mattos-Jr, D.; Boaretto, R.M.; Williams, L.E. Copper excess reduces nitrate uptake by Arabidopsis roots with specific effects on gene expression. J. Plant. Physiol. 2018, 228, 158-165. [CrossRef]

33. Weber, M.B.; Schat, H.; Ten Bookum-Van Der Maarel, W.M. The effect of copper toxicity on the contents of nitrogen compounds in Silene vulgaris (Moench) Garcke. Plant. Soil 1991, 133, 101-109. [CrossRef]

34. Akmukhanova, N.R.; Zayadan, B.K.; Sadvakasova, A.K.; Bolatkhan, K.; Bauenova, M.O. Consortium of Higher Aquatic Plants and Microalgae Designed to Purify Sewage of Heavy Metal Ions. Russ. J. Plant. Physiol. 2018, 65, 143-149. [CrossRef]

35. Zhu, X.; Dao, G.; Tao, Y.; Zhan, X.; Hu, H. A review on control of harmful algal blooms by plant-derived allelochemicals. J. Hazard. Mater. 2020, 123, 403. [CrossRef] [PubMed]

36. Zhou, L.; Chen, G.; Cui, N.; Pan, Q.; Song, X.; Zou, G. Allelopathic effects on Microcystis aeruginosa and allelochemical identification in the culture solutions of typical artificial floating-bed plants. Bull. Environ. Contam. Toxicol. 2019, 102, 115-121. [CrossRef] [PubMed]

37. Hua, Q.; Liu, Y.G.; Yan, Z.L.; Zeng, G.M.; Liu, S.B.; Wang, W.J.; Wang, Q.P. Allelopathic effect of the rice straw aqueous extract on the growth of Microcystis aeruginosa. Ecotoxicol. Environ. Saf. 2018, 148, 953-959. [CrossRef]

38. Castenholz, R.W. Phylum BX. Cyanobacteria. Oxygenic Photosynthetic Bacteria. In Bergey's Manual of Systematic Bacteriology, 2nd ed.; Boone, D.R., Castenholz, R.W., Garrity, G.M., Eds.; Springer: New York, NY, USA, 2001; pp. $473-487$.

39. Rippka, R.; Deruelles, J.; Waterbury, J.; Herdman, M.; Stanier, R. Generic assignments, strain histories and properties of pure cultures of cyanobacteria. J. Gen. Microbiol. 1979, 111, 1-61. [CrossRef]

40. Murashige, T.; Skoog, F. A revised medium for rapid growth and bio assays with tobacco tissue cultures. Physiol. Plant. 1962, 15, 473-497. [CrossRef]

41. Hadiyanto, A.G.; Pradana, L.; Buchori, C.; Budiyati, S. Biosorption of Heavy Metal $\mathrm{Cu}^{2+}$ and $\mathrm{Cr}^{2+}$ in Textile Wastewater by Using Immobilized Algae. Res. J. Appl. Sci. Eng. Technol. 2014, 7, 3539-3543. [CrossRef]

42. Wellburn, A.R.; Lichtenthaler, H. Formulae and Program to Determine Total Carotenoids and Chlorophylls A and B of Leaf Extracts in Different Solvents. Adv. Photosynth. Res. 1984, 2, 9-12.

43. Langer, C.L.; Hendrix, P.F. Evaluation of a persulfate digestion method for particulate nitrogen and phosphorus. Water Res. 1982, 16, 1451-1454. [CrossRef]

44. Zhou, G.J.; Peng, F.Q.; Zhang, L.J.; Ying, G.G. Biosorption of zinc and copper from aqueous solutions by two freshwater green microalgae Chlorella pyrenoidosa and Scenedesmus obliquus. Environ. Sci. Pollut. Res. 2012, 19, 2918-2929. [CrossRef] [PubMed] 